\title{
O professor remoto: a reinvenção da prática pela fluência digital
}

\author{
The remote teacher: the reinvention of practice by digital fluence \\ El maestro remoto: la reinvención de la práctica por fluencia digital
}

Recebido: 19/01/2021 | Revisado: 22/01/2021 | Aceito: 27/01/2021 | Publicado: 03/02/2021

\author{
Augusta Maria Fontes Veloso \\ ORCID: https://orcid.org/0000-0001-8523-4209 \\ Universidade Estadual de Santa Cruz, Brasil \\ E-mail: amfveloso@uesc.br \\ Viviane Briccia \\ ORCID: https://orcid.org/0000-0002-1480-5526 \\ Universidade Estadual de Santa Cruz, Brasil \\ E-mail: viviane@uesc.br
}

\begin{abstract}
Resumo
O presente artigo apresenta uma revisão bibliográfica, que é parte de uma pesquisa em construção, sobre o desenvolvimento da fluência digital na reinvenção da prática docente, no contexto atual mediado pela tecnologia. $\mathrm{O}$ objetivo deste texto é dialogar com os principais estudos nas áreas de Práticas Pedagógicas e Tecnologia, para identificar lacunas que ainda possam ser preenchidas na pesquisa em Educação. O levantamento bibliográfico foi realizado a partir de busca na base de dados da Biblioteca Eletrônica Scielo, dos quais foram selecionados três artigos. Este estudo aponta que, embora os recursos tecnológicos no contexto da necessidade do ensino remoto estejam presentes e atrelados a um processo de reinvenção da prática pedagógica, não haverá a garantia de desenvolvimento da fluência digital se não ocorrer um investimento na formação docente para o uso das tecnologias na Educação.
\end{abstract}

Palavras-chave: Prática docente; Tecnologia; Ensino remoto; Fluência digital.

\begin{abstract}
This article presents a bibliographic review, which is part of a research under construction, on the development of digital fluency in the reinvention of teaching practice, in the current context mediated by technology. The purpose of this text is to dialogue with the main studies in the areas of Pedagogical Practices and Technology, to identify gaps that can still be filled in research in Education. The bibliographic survey was carried out by searching the database of the Scielo Electronic Library, from which three articles were selected. This study points out that, although technological resources in the context of the need for remote education are present and linked to a process of reinventing pedagogical practice, there will be no guarantee of the development of digital fluency if there is no investment in teacher training for the use of technologies in Education.
\end{abstract}

Keywords: Teaching practice; Technology; Remote teaching; Digital fluency.

\section{Resumen}

Este artículo presenta una revisión bibliográfica, que forma parte de una investigación en construcción, sobre el desarrollo de la fluidez digital en la reinvención de la práctica docente, en el contexto actual mediado por la tecnología. El propósito de este texto es dialogar con los principales estudios en las áreas de Prácticas Pedagógicas y Tecnología, para identificar vacíos que aún pueden ser llenados en la investigación en Educación. El relevamiento bibliográfico se realizó mediante la búsqueda en la base de datos de la Biblioteca Electrónica Scielo, de la cual se seleccionaron tres artículos. Este estudio señala que, si bien los recursos tecnológicos en el contexto de la necesidad de la enseñanza a distancia están presentes y vinculados a un proceso de reinvención de la práctica pedagógica, no habrá garantía del desarrollo de la fluidez digital si no se invierte en la formación del profesorado para el uso de tecnologías en educación.

Palabras clave: Práctica docente; Tecnología; Enseñanza remota; Fluidez digital.

\section{Introdução}

As últimas décadas trouxeram para a sociedade uma série de transformações nas maneiras de se comunicar, de aprender, de ensinar e de produzir conhecimentos. Essas mudanças podem ser atribuídas à quantidade de informações geradas, as quais as pessoas estão expostas, e à grande quantidade de recursos tecnológicos disponíveis para tal. Com o aumento do acesso à internet e a popularização de equipamentos como os notebooks e smartphones, muitas pessoas, mesmo sem conhecimentos técnicos, se tornaram usuários habituais das tecnologias de informação e comunicação. No contexto atual, 
especialmente, em que o mundo vivencia a necessidade de isolamento social por conta do estado de calamidade na saúde pública, pela pandemia de um novo coronavírus - SARS-COV2, o tempo tem se apresentado como um tempo de incertezas, de propagação de notícias de todos os tipos, falsas e verdadeiras, do uso intenso de ferramentas tecnológicas e redes de internet que a cada dia estão mais desenvolvidas, além de ser um tempo de grande velocidade, expectativa e relevância para o conhecimento científico e tecnológico, especialmente nos estudos que buscam uma vacina eficaz e de alcance de distribuição, para a COVID 19.

A história avança, não de modo frontal como um rio, mas por desvios que decorrem de inovações ou de criações internas, de acontecimentos ou acidentes externos. A transformação interna começa a partir de criações inicialmente locais e quase microscópicas, efetua-se em meio inicialmente restrito a alguns indivíduos e surge como desvios em relação à normalidade. Se o desvio não for esmagado, pode, em condições favoráveis, proporcionadas geralmente por crises, paralisar a regulação que o freava ou reprimia, para, em seguida, proliferar de modo epidêmico, desenvolver-se, propagar-se e tornar-se tendência cada vez mais poderosa, produzindo a nova normalidade. (Morin, 2001)

A imposição desse novo tempo, dessa nova normalidade na vida das pessoas, que se apresenta com um aumento gigantesco da presença das tecnologias e que transforma as relações sociais e as formas de produção de conhecimento, exige que o campo da Educação urgentemente se reinvente, ressignificando as práticas e organização pedagógicas, para atender a demanda de um ensino que seja possível para o momento de distanciamento físico e que é ainda pouco conhecido, o Ensino Remoto.

Nesse sentido, cabe explicitar que, no contexto atual, com a suspensão das aulas presenciais, o Ministério da Educação, em caráter excepcional, autorizou que atividades de ensino fossem aplicadas por meio de ambiente virtual, ou seja, mediadas pela tecnologia. Com base em Pretto e Riccio (2010), "a imersão na rede, com a apropriação dos recursos tecnológicos digitais de comunicação, é parte tanto dos processos de aprendizagem como dos de formação" e ainda "a atuação na docência online leva o professor, inevitavelmente, a adentrar neste mundo virtual, repleto de possibilidades, que lhe possibilita o contato com outras vozes, outras reflexões, outras virtualizações e realidades”. Fica claro que toda essa contextualização exige um enfrentamento e uma nova postura dos professores, a partir da reflexão sobre suas práticas pedagógicas frente às possibilidades ampliadas para esse novo ensino desafiador.

Sendo assim, como garantir que os professores estejam preparados e possam, em seu percurso, desenvolverem sua fluência digital, para atuarem com as tecnologias digitais nas escolas através do ensino remoto, se em sua formação ainda encontram dificuldades e falta de investimentos para construir avanços?

Nessa perspectiva, este artigo pretende dialogar com estudos que se dedicam aos processos de formação docente para o uso de tecnologias e para o desenvolvimento de habilidades e fluência digital, que são de grande importância no contexto social e educacional atual, estando, portanto, correspondendo com as demandas visíveis na escola e que requisitam uma nova organização e prática do professor.

\section{Cibercultura, Tecnologias Digitais e Práticas Pedagógicas: fundamentação teórica}

O uso de tecnologias digitais em espaços educativos cresceu bastante nos últimos anos. A presença das tecnologias, especificadamente as de informação e comunicação nas escolas, implicou em uma mudança social e cultural e tem valorizado um novo tipo de conhecimento, que exige o domínio de habilidades no campo das ciências. É fato que a inserção das tecnologias nas escolas faz parte de uma cultura, a cultura digital - cibercultura, que nasceu com a internet e que seu acesso torna o ambiente um espaço ampliado de comunicação e informação. Segundo Pierre Lévy (1999), "a cibercultura expressa o surgimento de um novo universal, diferente das formas que vieram antes dele no sentido de que ele se constrói sobre a indeterminação de um sentido global qualquer". 
As transformações advindas da velocidade com que os recursos digitais avançam, perpassam pela reelaboração da estrutura cultural, principalmente no que diz respeito às relações sociais, homem x homem e homem x máquina. Pretto (2011) corrobora refletindo que "a apropriação das tecnologias digitais pode ser importante elemento no sentido de uma ampliação do acesso por boa parte da população que ainda está excluída da chamada cibercultura" e que "implanta-se a cultura da velocidade e essa associa-se, de forma intensa, com a velocidade com que são descartadas soluções tecnológicas que mal foram criadas". Nessa perspectiva, cabe olhar para as práticas com o uso das tecnologias como práticas culturais e sociais, como ações de sujeitos construídas de acordo com suas escolhas e condições reais de aplicabilidade. A cultura digital pressupõe saberes que se manifestam por rede e que, nas escolas, são mediadas pelo professor, assumindo esse importante papel na educação.

Formar para as novas tecnologias é formar o julgamento, o senso crítico, o pensamento hipotético e dedutivo, as faculdades de observação e de pesquisa, a imaginação, a capacidade de memorizar e classificar, a leitura e a análise de textos e de imagens, a representação de redes, de procedimentos e de estratégias de comunicação. (Perrenoud, 2000)

A importância da educação, da formação docente inicial e continuada, para promover a articulação de novos saberes nesse contexto da cultura digital, está para além da constituição de um sujeito mero usuário das tecnologias, mas, para a construção de um "sujeito historicamente situado.” (Pimenta, 2012) Nesse sentido, refletir e alimentar as práticas pedagógicas de saberes e experiências, é materializar a formação docente, em ação. Pimenta (2012) sustenta que:

(...) trabalhar o conhecimento na dinâmica da sociedade multimídia, da globalização, da multiculturalidade, das transformações nos mercados produtivos, na formação dos alunos, crianças e jovens, também eles em constante processo de transformação cultural, de valores, de interesses e necessidades, requer permanente formação, entendida como ressignificação identitária dos professores.

Em suma, a cibercultura é a cultura digital que se constitui pela via da sociedade contemporânea da informação e comunicação, que transpõe os limites da técnica e impõe um processo de formação para docentes no sentido do desenvolvimento de competências, para a ressignificação das suas práticas pedagógicas e organização didática e garantia do seu papel de mediador nos processos de construção de conhecimentos.

\section{Observando Relações entre Formação Docente e Tecnologias Digitais}

Esta pesquisa tem natureza qualitativa, visto que o estudo investigativo que se propõe exige maior proximidade com o problema, sendo de grande valia a interpretação do mesmo pelas pesquisadoras. Nesse sentido, Ludke e André (2013) afirmam que a pesquisa qualitativa ocorre num ambiente natural com coleta de dados e que o pesquisador é o principal instrumento, seguindo um processo indutivo para a análise de dados e informações. Como percurso metodológico adotou-se o método bibliográfico que, segundo Köche (2011), se desenvolve tentando explicar um problema, utilizando o conhecimento disponível a partir das teorias publicadas em livros ou obras congêneres.

Nesse espaço apresentamos os artigos que foram encontrados e selecionados por meio do mecanismo de busca na Biblioteca Eletrônica Scielo. Utilizando as palavras "formação docente”, "tecnologias digitais” e "práticas pedagógicas”, a pesquisa resultou em três trabalhos para o delineamento do estudo. Quando se relacionou a palavra "fluência digital" às demais palavras no mecanismo de busca, o resultado se restringiu a um único trabalho encontrado, dos já listados. O quadro abaixo apresenta o levantamento realizado. 
Quadro 1 - Artigos de periódicos nacionais.

\begin{tabular}{|c|c|c|c|}
\hline Autor(es) & Título & Palavras-chaves & Revista/Qualis \\
\hline $\begin{array}{l}\text { Modelski, } \\
\text { Casartelli (2019) }\end{array}$ & $\begin{array}{l}\text { Tecnologias digitais, } \\
\text { formação docente e } \\
\text { práticas pedagógicas }\end{array}$ & $\begin{array}{l}\text { Tecnologias digitas; } \\
\text { Formação docente; } \\
\text { Práticas pedagógicas }\end{array}$ & Educação e Pesquisa, A1. \\
\hline $\begin{array}{l}\text { Lima } \\
(2016)\end{array}$ & $\begin{array}{l}\text { Projeto UCA em } \\
\text { Tiradentes: significações } \\
\text { de duas professoras } \\
\text { quanto às tecnologias } \\
\text { digitais de informação e } \\
\text { comunicação no contexto } \\
\text { escolar. }\end{array}$ & $\begin{array}{lr}\text { Políticas } & \text { Públicas; } \\
\text { Cibercultura; } & \text { Tecnologias } \\
\text { Digitais; } & \text { Prática } \\
\text { Pedagógica. } & \end{array}$ & Educar em Revista, A1. \\
\hline Martins e Maschio (2014) & $\begin{array}{l}\text { As tecnologias digitais na } \\
\text { escola e a formação } \\
\text { docente: representações, } \\
\text { apropriações e práticas. }\end{array}$ & $\begin{array}{l}\text { Escola pública básica; } \\
\text { Tecnologias. Professores; } \\
\text { Brasil. }\end{array}$ & $\begin{array}{lr}\text { Revista } & \text { Eletrônica } \\
\text { "Actualidades } & \\
\text { Investigativas } & \text { em } \\
\text { Education", B1 } & \end{array}$ \\
\hline
\end{tabular}

Fonte: Autoras.

O trabalho de Modelski, Giraffa e Casartelli (2019) trata de um estudo sobre "a formação docente em tempos de cibercultura e sua inter-relação com conhecimentos, habilidades e atitudes para atuação de professores no cenário educacional influenciado pelo uso das Tecnologias Digitais (TDs)". O texto reflete sobre uma das competências, a fluência digital, evidenciada nos docentes que desenvolvem boas práticas com o uso das tecnologias. A partir das experiências dos docentes, o estudo discute os desdobramentos da fluência digital e a sua contribuição para aqueles que desejam utilizar ou criar práticas pedagógicas com tecnologias digitais. Em suas reflexões, os autores consideram que "o professor contemporâneo utiliza artefatos tecnológicos para organizar suas aulas, para comunicar-se, para pesquisar, ou seja, ele é usuário de tecnologia em algum nível. No entanto, cabe salientar que o fato de o professor ser usuário de tecnologia não lhe garante a transposição didática”. Esse estudo demonstrou que os professores que conseguem desenvolver sua fluência digital, vêm consequentemente modificando suas práticas pedagógicas, utilizando as tecnologias digitais. Neste caso, o foco da formação docente encontra-se na "ambiência tecnológica" e nas "estratégias didáticas" utilizadas em redes de trocas entre professores dentro e fora de sala de aula, alinhando para isso, práticas de estudo e de aprendizagem.

O texto de Lima e Nascimento (2016) apresenta o resultado de um recorte em pesquisa de doutorado que investigou "os desdobramentos de políticas públicas de inclusão digital nas práticas pedagógicas". Nesse recorte, o enfoque se deu no estudo das influências do Projeto Um Computador por Aluno (UCA) ${ }^{1}$, na apropriação docente das tecnologias digitais de informação e comunicação e nas práticas pedagógicas. $\mathrm{O}$ artigo procurou "sintetizar as condições contextuais da implantação do Projeto na cidade de Tiradentes e algumas das significações de duas professoras que trabalharam na vigência do mesmo Projeto". Os autores explicitam que, embora as políticas públicas de inclusão digital procurem aparelhar as escolas com as tecnologias digitais de comunicação e informação, atendendo ao contexto da cibercultura, e busquem estimular novas práticas de ensino e de aprendizagem por meio das ações e produções docente e discente, sinalizam que essas ações ainda não são suficientes para o "desenvolvimento efetivo da cultura digital no âmbito escolar". Sendo assim, concluem que o apoderamento docente das tecnologias digitais da informação e comunicação e consequente "reconfiguração pedagógica" estão condicionadas

${ }^{1}$ Programa Um Computador por Aluno (UCA) foi implantado com o objetivo de intensificar as tecnologias da informação e da comunicação (TIC) nas escolas, por meio da distribuição de computadores portáteis aos alunos da rede pública de ensino. Foi um projeto que complementou as ações do MEC referentes a tecnologias na educação, em especial os laboratórios de informática, produção e disponibilização de objetivos educacionais na internet dentro do ProInfo Integrado que promove o uso pedagógico da informática na rede pública de ensino fundamental e médio. Página do FNDE/MEC, acesso em 04/12/2020. https://www.fnde.gov.br/index.php/programas/proinfo/eixos-de-atuacao/projeto-um-computadro-por-aluno-uca 
ao acesso a essas tecnologias, ao suporte técnico e pedagógico frequente e à formação docente continuada, oportunizando experiências contextualizadas para o uso pedagógico com tecnologias. Além disso, o resultado das análises dos autores trazem dois fatores também determinantes para a uma possível mudança pedagógica com relação ao uso das tecnologias na escola: o tempo, atrelado a uma perspectiva a longo prazo de conscientização docente quanto às potencialidades das tecnologias; e uma "revisão das crenças pedagógicas”, diante do reconhecimento de que a presença das tecnologias digitais no ambiente escolar, na maioria dos contextos, desestabiliza o "fazer pedagógico" dos docentes, acarretando algumas resistências. Dessa forma, fazse necessário vencer todos os obstáculos técnicos, logísticos, pedagógicos e culturais para que uma reconfiguração das práticas aconteça.

Por fim, o estudo de Martins e Maschio (2014) analisa "a formação docente para o uso das novas tecnologias na escola", a partir da compreensão das "representações, apropriações e práticas de professores da educação básica". As autoras apontam que as tecnologias digitais já extrapolaram os espaços sociais e se fazem presentes nos ambientes escolares, embora o seu uso ainda incipiente tenha produzido impactos e promovido reflexões e estudos acerca do fortalecimento da adoção e da integração dessa tecnologia digital na formação de professores. O estudo sinaliza que um dos desafios da formação docente para o uso das tecnologias é desenvolver nos professores a percepção da potencialidade e da abrangência dos recursos digitais na aplicabilidade pedagógica. Foram investigadas as maneiras como os "professores pensam, olham e constroem a realidade da sala de aula a partir do uso das novas tecnologias digitais", as representações; e a "interpretação das representações e prescrições formalizada nas práticas”, a apropriação. Quanto à representação, ficou evidente na pesquisa que os professores consideram as tecnologias digitais muito importantes para o processo de ensino aprendizagem e o seu uso é "fundamental para desenvolver atividades criativas e motivadoras", contemplando as demandas da "sociedade cibercultural". Dessa forma, o trabalho apontou que limitar-se à inserção dos recursos digitais na escola não é suficiente para promover uma transformação pedagógica, mas, que fundamentalmente as "representações e apropriações materializadas nas práticas são capazes de produzir uma nova cultura escolar". O maior desafio atual está posto em dois aspectos: a) estrutural, pouca infraestrutura das escolas para oferecer suporte às novas tecnologias; e b) humano, pouco domínio metodológico de docentes no uso dos recursos digitais. As autoras constatam que as novas possibilidades de ensinar e de aprender, provocadas pelas transformações da sociedade da informação, vão permitir uma reinvenção da cultura escolar nos variados níveis do sistema de ensino brasileiro.

\section{Considerações Finais}

Com base na leitura dos textos apresentados, podemos ressaltar alguns aspectos convergentes sobre o desenvolvimento da fluência digital na reinvenção da prática docente, no contexto atual de ensino remoto mediado pela tecnologia.

Um primeiro aspecto diz respeito à necessidade de identificar o contexto social e educativo ao qual vivemos, na contemporaneidade, implicados numa sociedade da informação e comunicação como produtores e consumidores de culturas, a cibercultura especialmente. Essa ambientação nos impõe reflexões e discussões sobre a operacionalização dos conhecimentos adquiridos a partir do uso dos recursos digitais e suas implicações. Para além de um uso meramente mecânico e técnico automatizado, faz-se necessário o desenvolvimento de competências, como exemplo a fluência digital, que poderão contribuir e produzir significados reais aos que desejarem criar situações metodológicas com utilização das tecnologias digitais, ressignificando sua prática pedagógica.

Adentramos no segundo aspecto, que concerne às oportunidades para formação docente, inicial e continuada, alinhando teorias às práticas pedagógicas. Os estudos levantados apontam e sugerem que a formação de professores aconteça dentro de um processo gradual, que requer tempo, investimento pessoal e profissional do professor revendo crenças e resistências, oportunizando ambiências tecnológicas e espaços de socialização de experiências didáticas, para promover uma 
mudança contínua na percepção e para construção de práticas mais modernas e inovadoras.

Retomando e considerando o contexto da atualidade, diante da emergência de transposição do Ensino Presencial para o Ensino Remoto, por conta da pandemia do coronavírus e do distanciamento físico, o tempo e a demanda pressupõem uma reinvenção imediata, posta, de ações e processos intencionais pedagógicos contínuos e assegurados, impondo ao professor um movimento de mudança de postura acelerada, que avança num ritmo veloz, como das tecnologias. Com mais experiências e competências adquiridas, segue o Professor Remoto, caminhando na trilha da sua formação.

Em suma, sugere-se que novos trabalhos de investigação adentrem nos caminhos da formação pessoal e profissional do professor, mitigando as dificuldades impostas ao fazer pedagógico na contemporaneidade.

\section{Referências}

Koche, J. C. (2011). Fundamentos de metodologia científica: Vozes.

Lévy, P. (1999). Cibercultura. (34a ed.).

Lima, M., \& Nascimento, S. (2016) Projeto UCA em Tiradentes: significações de duas professoras quanto às tecnologias digitais de informação e comunicação no contexto escolar. Educar em Revista, Curitiba, Brasil, 61, 223-240.

Ludke, M., \& Andre, M. E. D. A. (2013). Pesquisas em educação: uma abordagem qualitativa: E.P.U.

Martins, O., \& Marchio, E. (2014) As tecnologias digitais na escola e a formação docente: representações, apropriações e práticas. Revista Actualidades Investigativas em Educación, 14(3).

Modelski, D., Giraffa, L., \& Casartelli, A. (2019) Tecnologias digitais, formação docente e práticas pedagógicas. Revista Educação e Pesquisa, São Paulo, 45, e180201.

Morin, E. (2001) Os sete saberes necessários à Educação do futuro. (4a ed.). Cortez. UNESCO.

Perrenoud, P. (2000) Dez novas competências para ensinar. Trad. Patrícia Chittoni Ramos: Artes Médicas Sul.

Pimenta, S. (2012). Formação de professores: identidade e saberes da docência. In: Saberes Pedagógicos e atividade docente. (8a ed.). Cortez.

Pretto, N. (2011) O desafio de educar na era digital. 24 (1), 95-118. Universidade do Minho.

Pretto, N., \& Riccio, N. (2010). A formação continuada de professores universitários e as tecnologias digitais. Revista Educar, 37, 153-169. Editora UFPR. 